\title{
ANÁLISE DA DESIDRATAÇÃO DE SPIRULINA PLATENSIS POR INFRAVERMELHO
}

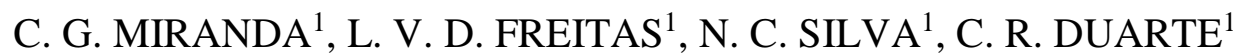 \\ e M. A. S. BARROZO ${ }^{1}$ \\ ${ }^{1}$ Universidade Federal de Uberlândia, Faculdade de Engenharia Química \\ E-mail para contato: cecilia.guerino@gmail.com
}

\begin{abstract}
RESUMO - A Spirulina platensis é uma espécie de microalga que pertence ao filo Cyanobacteria. Muito conhecida pelos seus vários fins comerciais, é utilizada principalmente como suplemento nutricional por apresentar elevada variedade de nutrientes essenciais, o que torna necessário uma melhor análise da viabilidade da mesma. A Spirulina também possui um alto teor de umidade, aumentando os risos de contaminação por micro-organismos, dessa forma, a desidratação se mostra uma alternativa bastante viável para sua preservação e armazenamento. Dentre as técnicas disponíveis, o uso de radiação infravermelha se destaca devido ao seu potencial e eficiência, permitindo desidratações rápidas e uniformes. Assim, o objetivo desse trabalho foi avaliar os efeitos da desidratação por infravermelho da Spirulina platensis em diferentes temperaturas e seus impactos nos compostos bioativos presentes, a fim de verificar sua qualidade para uma futura utilização como alimento. Pôde-se verificar que após a desidratação, em condições específicas, foi possível obter teores de bioativos próximos ou até mesmo superiores à Spirulina in natura.
\end{abstract}

\section{INTRODUÇÃO}

O termo Spirulina se refere a um grande número de espécies de microalgas, cujas espécies mais comumente utilizadas na dieta são S. maxima, S. platensis e S. fusiformis (Marles et al., 2010). Também conhecida como alga verde-azulada, a Spirulina é uma fonte segura e natural de uma elevada variedade de nutrientes essenciais, tais como pró-vitaminas, minerais, proteínas e ácidos graxos poli-insaturados (Miranda et al., 1998). A cultura desta microalga é atraente para vários fins comerciais, tais como a sua utilização como suplemento nutricional para seres humanos e animais, material adsorvente de metais pesados, tratamento de águas residuais e fonte de metabólitos ativos na indústria farmacêutica e cosmética. (Kepekçi \& Saygideger et al., 2012).

O alto teor de degradação das microalgas ocorre devido a seu elevado conteúdo de água. Assim, torna-se necessário adotar métodos de secagem para evitar perdas neste sentido. A técnica de secagem é provavelmente o método mais antigo e importante de preservação de alimentos. A remoção de umidade previne o crescimento e reprodução de micro-organismos que causam deterioração do alimento. Esta operação oferece uma redução significativa de massa e volume, minimizando custos com embalagem, armazenamento e transporte (Mujumdar et al., 1995). 
Dentre as mais variadas metodologias de desidratação conhecidas, o uso da radiação infravermelha tem recebido atenção recente. Quando a radiação infravermelha é utilizada para aquecer ou desidratar materiais úmidos, a mesma penetra no material exposto e sua energia é convertida em calor. Assim, o infravermelho é apropriado para desidratar finas camadas de material com grandes superfícies expostas a radiação, produzindo um aquecimento mais eficiente e uniforme, podendo resultar em menores tempos de desidratação e melhores características de qualidade, quando comparado aos métodos convencionais, como o ar quente (Hebbar \& Rostagi et al., 2001; Sakai \& Hanzawa, 1994).

Em face do exposto, o objetivo desse trabalho foi avaliar os efeitos da desidratação por infravermelho da Spirulina platensis em diferentes temperaturas e seus impactos nos compostos bioativos (fenólicos, flavonoides, ácido cítrico e ficocianina) presentes na mesma, a fim de verificar sua qualidade para utilização como suplemento alimentar.

\section{MATERIAL E MÉTODOS}

\subsection{Material utilizado}

A microalga Spirulina platensis (Figura 1a) foi fornecida pela empresa Brasil Vital, localizada em Anápolis, no Estado de Goiás. A empresa forneceu as amostras previamente filtradas, as quais foram separadas, empacotadas e congeladas em freezer à $-18^{\circ} \mathrm{C}$, onde ficavam até o momento dos experimentos.

\subsection{Aparato Experimental}

A desidratação por infravermelho da Spirulina foi realizada em um secador da fabricante Gehaka, modelo IV 2500 (Figura 1b), constituído por um emissor infravermelho, um sensor de temperatura do tipo Platina (PT1000) e um suporte ligado diretamente a uma balança, sob o qual foi colocado um prato com a amostra uniformemente distribuída. $\mathrm{O}$ material foi desidratado nas temperaturas de $65^{\circ} \mathrm{C}, 80^{\circ} \mathrm{C}, 95^{\circ} \mathrm{C}$ e $110^{\circ} \mathrm{C}$ até que não houvesse mais variação na umidade, ou seja, até que o material atingisse o equilíbrio.

Figura 1 - Biomassa de Spirulina utilizada (a) e secador por infravermelho (b)
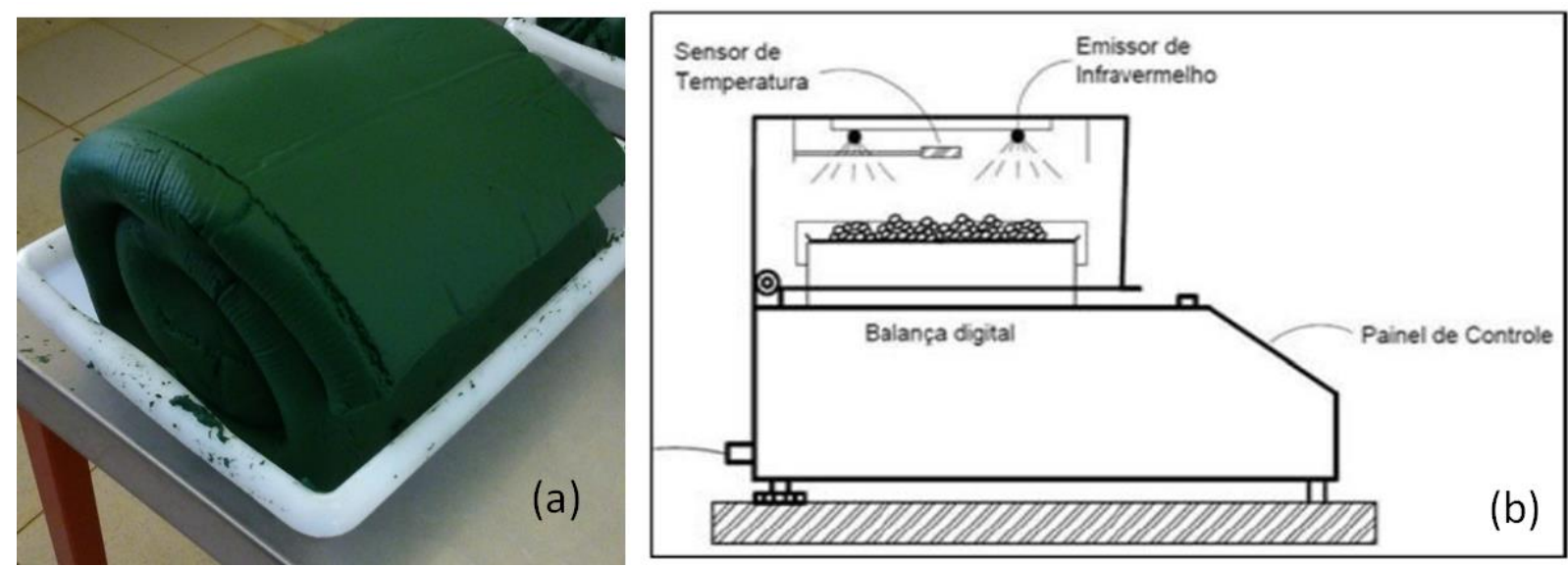


\subsection{Atividade de Água (Aw)}

Segundo Cano-Chauca et al. (2004), a remoção de umidade provoca a diminuição da atividade de água do produto, inibindo o desenvolvimento de microrganismos e retardando deteriorações de origem físico-química. Dessa forma, além da umidade (definida pelo método da estufa $-105^{\circ} \mathrm{C}$ por $24 \mathrm{hs}$ ) foi medida a atividade de água da Spirulina durante o processo de desidratação pelo equipamento Lab-Swift Aw (Novasina).

\subsection{Análise dos Compostos Bioativos}

Quatro diferentes compostos bioativos foram analisados, tanto para a Spirulina in natura (antes da desidratação) quanto para o material desidratado. Todas as análises foram realizadas em triplicata.

Teor de Fenólicos Totais (TPC): A determinação do teor de compostos fenólicos totais foi feita pelo método de Folin Ciocalteau, utilizando ácido gálico como padrão de acordo e leitura em espectrofotômetro à $622 \mathrm{~nm}$, conforme descrito por Singleton \& Rossi et al. (1965). Os resultados foram expressos em mg de ácido gálico / $100 \mathrm{~g}$ amostra em base seca.

2.3.2 - Teor de Flavonoides Totais (TFC): O teor de flavonoides foi determinado pelo método colorimétrico, segundo Zhishen et al. (1999), também com leitura em espectrofotômetro à $450 \mathrm{~nm}$, utilizando a rutina como padrão. Os resultados foram expressos em $\mathrm{mg}$ de rutina / $100 \mathrm{~g}$ amostra em base seca.

2.3.3 - Acidez (ATT): A análise da presença do ácido cítrico na amostra, foi realizada de acordo com o método da Association of Official Analytical Chemists - AOAC (1995), titulando as amostras com $\mathrm{NaOH}$ padronizado até a viragem. Os resultados foram expressos em mg de ácido cítrico / $100 \mathrm{~g}$ amostra em base seca.

2.3.4 - Teor de Ficocianina (TF): Para determinar o teor de Ficocianina da amostra, macerou-se as amostras com água e a solução obtida foi submetida à leitura em espectrofotômetro, conforme metodologia descrita por Costa et al. (2015). As leituras foram feitas nas absorbâncias de 620 e $652 \mathrm{~nm}$. Os resultados foram expressos em g ficocianina/ $100 \mathrm{~g}$ amostra em base seca.

\section{RESULTADOS E DISCUSSÕES}

\subsection{In Natura}

Tabela 1 - Resultados para Spirulina in natura

\begin{tabular}{|c|c|}
\hline Análises & Resultados / 100 g de amostra seca \\
\hline Fenólicos (TPC) & $252,40 \pm 13,77 \mathrm{mg}$ ácido gálico \\
\hline Flavonoides (TFC) & $4,83 \pm 0,25 \mathrm{mg}$ rutina \\
\hline Acidez (ATT) & $2173,68 \pm 179,32 \mathrm{mg}$ ácido cítrico \\
\hline Ficocianina & $8,75 \pm 0,51 \mathrm{~g}$ ficocianina \\
\hline Umidade & $82,40 \pm 0,92 \%$ \\
\hline
\end{tabular}


A Tabela 1 apresenta os teores dos compostos bioativos e a umidade da Spirulina platensis in natura. O material apresentou alta umidade e teores consideráveis de compostos bioativos, em destaque para a ficocianina.

\subsection{Parâmetros de Secagem}

Os resultados da análise de atividade de água, do tempo de desidratação e da umidade resultante aos finais dos experimentos estão expressos na Tabela 2. Pôde-se observar que em todas as condições analisadas a atividade de água se manteve em valores abaixo de 0,6, ou seja, dentro do esperado para que não houvesse crescimento de micro-organismos (Celestino et al., 2010). Verificou-se também que com o aumento da temperatura o tempo de desidratação necessário diminui, assim como o teor de umidade.

Tabela 2 - Umidade final, Aw e Tempo de Desidratação da Spirulina por Infravermelho

\begin{tabular}{|c|c|c|c|}
\hline Temperatura & Umidade Final (\%) & $\begin{array}{c}\text { Atividade de Água } \\
(\mathrm{Aw})\end{array}$ & $\begin{array}{c}\text { Tempo de } \\
\text { Desidratação (min) }\end{array}$ \\
\hline $65^{\circ} \mathrm{C}$ & $12,92 \pm 0,46$ & 0,503 & 600 \\
\hline $80^{\circ} \mathrm{C}$ & $4,97 \pm 0,39$ & 0,344 & 330 \\
\hline $95^{\circ} \mathrm{C}$ & $5,12 \pm 0,11$ & 0,350 & 177 \\
\hline $110^{\circ} \mathrm{C}$ & $4,25 \pm 0,08$ & 0,415 & 117 \\
\hline
\end{tabular}

\subsection{Compostos Bioativos}

Os resultados de compostos bioativos obtidos nos experimentos realizados e seu comparativo com os resultados da Spirulina in natura estão expressos na Figura 2.

O Teor de Fenólicos Totais (TFC) obtido nos experimentos pode ser observado na Figura 2a. Embora o aumento da temperatura tenha provocado menores tempos de desidratação, os teores de fenólicos totais sofreram uma considerável redução, indicando degradação desse composto devido as altas temperaturas. Somente na desidratação realizada a temperatura de $65^{\circ} \mathrm{C}$ foi possível obter teores de fenólicos levemente superiores ao do material in natura, mesmo com o alto tempo de desidratação. Isso aponta que os fenólicos são impactados mais fortemente pela temperatura do que pelo tempo. Tal aumento acima dos valores da Spirulina in natura é justificado por Chism \& Haard et al. (1996) como uma liberação dos compostos da matriz interna do material durante o processo de remoção de umidade, através do rompimento de fibras e outras estruturas internas.

A Figura $2 b$ expõe os resultados obtidos para os Teores de Flavonoides Totais (TFC). Assim como nos compostos fenólicos, houve uma maior influência da temperatura de processo quando comparada ao tempo de exposição. Porém, em todas as condições analisadas, os resultados foram menores que do material in natura, indicando degradação dos flavonoides devido à exposição ao infravermelho. A temperatura ideal encontrada para a desidratação foi de $65^{\circ} \mathrm{C}$, onde o impacto provocado pela exposição ao infravermelho foi menor, resultando em um maior teor de flavonoides.

A Acidez (ATT) expressa no teor de ácido cítrico obtido nos experimentos está expressa na Figura 2c. Observou-se que a exposição ao infravermelho pouco impactou os 
teores desse composto, obtendo-se valores próximos e até mesmo superiores aos teores de ácido cítrico da amostra in natura. Tal comportamento pode ser justificado mais uma vez pela liberação desses compostos da matriz interna da biomassa durante a remoção de umidade (Chism \& Haard, 1996; Veja-Gálvez et al., 2009). Mais uma vez, os melhores resultados foram obtidos para temperatura de $65^{\circ} \mathrm{C}$.

Os resultados alcançados para os níveis de Ficocianina (TF) estão expressos na Figura 2d. Observou-se que em todos os experimentos os níveis de ficocianina ficaram abaixo dos obtidos para a microalga in natura. Deve-se ressaltar também a ocorrência do mesmo comportamento observado para os outros compostos expostos acima: melhores resultados nas menores temperaturas, com destaque para a temperatura de $65^{\circ} \mathrm{C}$.

Figura 2 - Teor de Compostos Bioativos obtidos após a desidratação por infravermelho

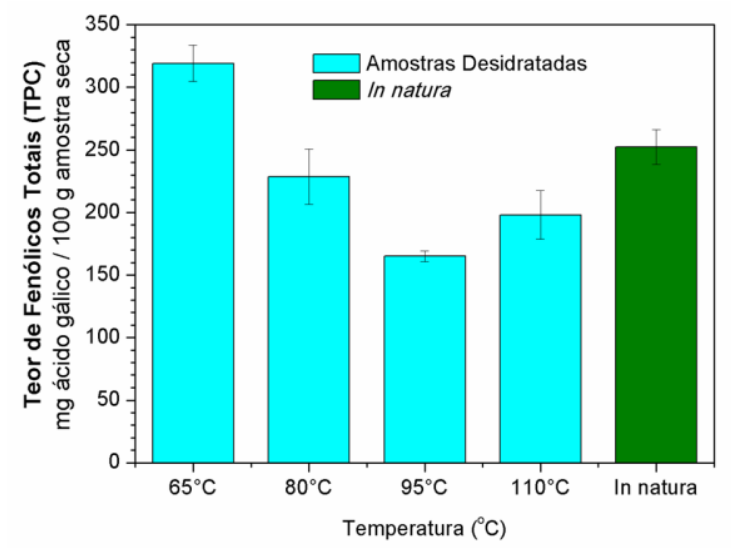

(a)

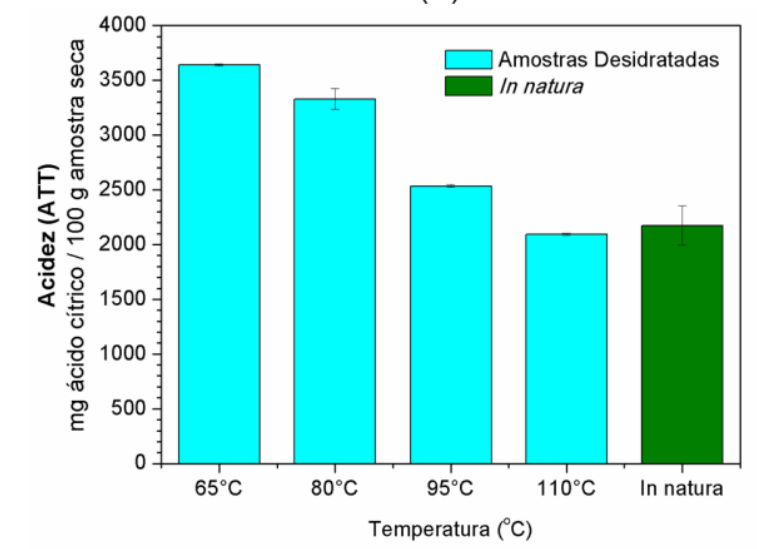

(c)

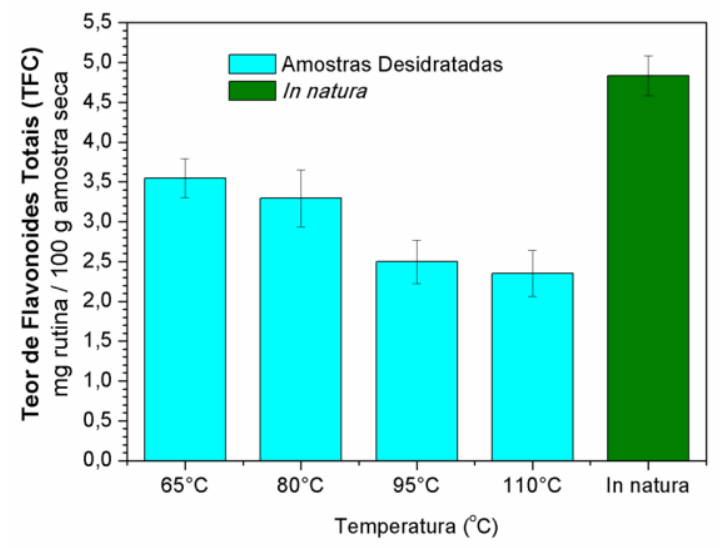

(b)

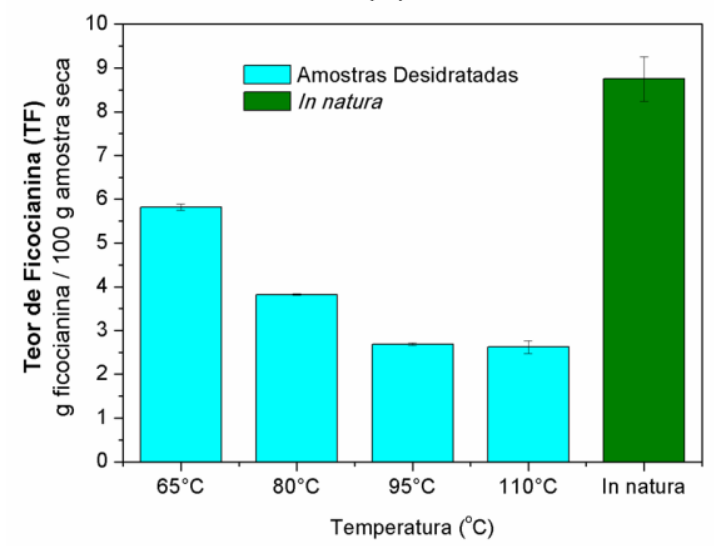

(d)

\section{CONCLUSÃO}

O método de desidratação por infravermelho se mostrou eficiente permitindo desidratar a microalga Spirulina de forma satisfatória. Apesar de temperaturas mais elevadas gerarem menores tempos de desidratação, foi constatado que o ideal é desidratar a Spirulina em temperaturas mais baixas como $65^{\circ} \mathrm{C}$, onde o tempo de secagem foi maior, mas os teores de compostos bioativos obtidos foram próximos e até mesmo superiores aos obtidos no material in natura. 


\section{BIBLIOGRAFIA}

AOAC, Association of Official Analytical Chemistics. Official Methods of Analysis, Gaithersburg, MD, 1995.

CANO-CHAUCA M.; RAMOS, M. A.; STRINGHETA, C. P.; MARQUES, J. A.; IBRAHIM, S. P. Curvas De Secagem E Avaliação da Atividade de Água da Banana passa. B.Ceppa, Curitiba, v. 22, n. 1 p. 121-132, 2004.

CELESTINO, S.M.C. Princípios de secagem de alimentos. Planaltina, DF: Empraba Cerrados, 51p., 2010.

COSTA, B. R.; RODRIGUES, M. C.; ROCHA, S. F., POHNDORF, R. S.; LARROSA, A. P.; PINTO, L. A. Optimization of Spirulina sp. Drying in Heat Pump: Effects on the Physicochemical Properties and Color Parameters. J. Food Process. Pres., v. 40(5), p. 934-942, 2015.

CHISM, G. W.; HAARD, N. F. Characteristics of edible plant tissues. Em: Food Chem, Fennema, O. R.; Editora Dekker, New York, 3a Ed.; 943 - 1011, 1996.

HEBBAR, H. U.; ROSTAGI, N. K. Mass transfer during infrared drying of cashew kernel, $J$. Food Eng., v. 47, p.1-5, 2001.

KEPEKÇI, R. A.; SAYGIDEGER, S. D. Enhancement of phenolic compound production in Spirulina platensis by two-step batch mode cultivation. J. Appl. Phycol. v. 24, p. 897905, 2012.

MARLES, R. J.; BARRETT, M. L.; BARNES, J. United States pharmacopeia safety evalution of Spirulina. Crit Rev Food Sci Nutr. 51(7): p. 593-604, 2010.

MIRANDA, M. S.; CINTRA, R. G.; BARROS, S. B. M.; MANCINI-FILHO, J. Antioxidant activity of the microalga Spirulina maxima. Braz. J. Med. Biol. Res. v. 31, p.1075-1079, 1998.

MUJUMDAR, A. S. Handbook of industrial drying. 2 ed. New York: Marcel Dekker, 1995.

SAKAI, N.; HANZAWA, T. Application and advances in far infrared heating in Japan Trends, Food Sci. Tech., v. 5(11), p. 357-362, 1994.

SINGLETON, V. L.; ROSSI, J. A., Colorimetry of total phenolics with phosphomolibidic, phosphotungistic acid reagents, Am. J. Enol. Vitic., v. 16, p. $144-158,1965$.

VEGA-GÁLVEZ, A.; DI SCALA, K.; RODRÍGUEZ, K.; MIRANDA, M.; LÓPEZ, J.; PEREZ-WON, M. Effect of air-drying on physico-chemical properties, antioxidant capacity, colour and total phenolic content, Food Chem., v. 117(4), p. 647-653, 2009.

ZHISHEN, J.; MENGCHENG, T.; JIANMING, W. The determination of flavonoid contents in mulberry and their scavenging effects on superoxide radicals, Food Chem., v. 64, p. $555-559,1999$. 